\title{
Perceptions and Practice of Use of Generic Medicines by Intern Doctors at A Tertiary Care Teaching Hospital - A Cross Sectional Study
}

\author{
. Alay K. Singhal ${ }^{1}$, Manish N. Solanki ${ }^{2 *}$,. Darshan J. Dave ${ }^{3}$ \\ ${ }^{1}$ Drug safety Physician, APCER lifescience Ltd., Mondeal heights, Wing A, 16th floor, ISCON cross road, Ahmedabad, Gujarat, India \\ ${ }^{2}$ Associate Professor, Department of Pharmacology, B. J. Medical College, Civil Hospital Campus, Ahmedabad, Gujarat, India \\ ${ }^{3}$ Professor \& Head, Department of Pharmacology, GMERS Medical College, Gandhinagar, Gujarat, India
}

DOI: $10.36348 /$ sjmps.2019.v05i11.009

| Received: 06.11.2019| Accepted: 19.11.2019| Published: 22.11.2019

*Corresponding author: Dr. Manish N. Solanki

\section{Abstract}

Introduction: As we aim to cater high-quality health-care system to the masses with limited available resources, increased usage of generic medicines can improve affordability of the health care without compromising the quality. The attitude of healthcare providers is a significant challenge towards dealing with the rising healthcare cost. It is during internship that attitudes of future physicians towards prescribing are developed. Data regarding knowledge, attitude and practice of intern doctors for the use of generic medicines are lacking. Objectives: The study was conducted to assess knowledge, attitude and practice of intern doctors regarding use of generic medicines at a tertiary care teaching hospital. Materials and Methods: A questionnaire based cross sectional study was conducted after the approval of institutional ethics committee among the intern doctors at tertiary care teaching hospital, who were willing to respond to the study questionnaire were enrolled. The pre-validated questionnaire with 11 questions regarding knowledge, attitude and practice were sent to the participants via email. Responses were submitted online and data was analyzed in frequency and percentage. Results: A total of 163 intern doctors responded to questionnaire. Out of 163 intern doctors, 93\% interns have knowledge of regulation, $60.9 \%$ know the meaning of generic medicines while $74.2 \%$ had knowledge regarding source of generic medicine. $77.4 \%$ interns intended to prescribe by generic name. Generic medicine prescribing is found higher than brand medicine prescribing in interns. Conclusion: The study showed that the intern doctors not only have adequate knowledge about the generic medicines but they also support, favour and practice the use of generic medicine in clinical practice.

Keywords: Generic Medicines Knowledge Practice Intern doctors Perception.

Copyright @ 2019: This is an open-access article distributed under the terms of the Creative Commons Attribution license which permits unrestricted use, distribution, and reproduction in any medium for non-commercial use (NonCommercial, or CC-BY-NC) provided the original author and source are credited.

\section{INTRODUCTION}

Health care expenditure is one of the major economic burden for any individual now a days. Among the health care expenditure, the cost of drug therapy accounts for more than $80 \%$ [1-4]. The high cost of certain medicines has made the treatment of many common and uncommon diseases unaffordable to the poor and a strain on the budgets of even middleclass citizens. For patients who suffer from diabetes or hypertension who need medications life long, cost of the drug therapy will be a great economic burden [5]. A huge proportion of health budget of most developing countries goes to purchasing drugs needed to treat diseases of public health importance [6]. Therefore, access to treatment is challenged by the availability of affordable medicines. One-third of the population in the developing world does not have access to medicines
[6]. Accessibility is often hampered, among others, by high prices of these drugs [7]. As a strategy to increase access, most developed and developing countries have instituted measures to reduce expenditure on medicines. One such approach involves promoting the use generic medicines among healthcare providers [8]. Generic drugs are typically less expensive than brand-name drugs with same therapeutic effect [1].

According to the United States Food and Drug Administration (FDA), generic drug is defined as a drug that has the same characteristics as a branded drug in active ingredient, strength, route of administration, safety, dosage form, performance, quality and intended use. Generic drugs need to be bioequivalent to the branded drug to be licensed for marketing [9]. Generic medications may however differ from branded ones in 
shape, colour, test, and names [10]. A generic medicine is a multisource pharmaceutical product which is intended to be interchangeable with the originator product and is marketed after patents and other exclusivity rights of the innovator pharmaceutical company have expired [11, 12]. Generic substitution is considered as a major cost minimizing strategy meant to contain pharmaceutical expenditure without compromising healthcare quality [13-16]. The successful implementation of the generic medicine substitution policy in many countries around the world hinges on healthcare providers' knowledge and perception of generic medicines [17].

Clause 1.5 of the Indian Medical Council (Professional Conduct, Etiquette, and Ethics) Regulations, 2002, stated as follows: "Use of generic names of drugs: Every physician should, as far as possible, prescribe drugs with generic names and he/she shall ensure that there is a rational prescription and use of drugs." This clause encouraged the prescription of generic drugs but did not forbid the prescription of brands. The clause was modified on September 21, 2016 (No. MCI-211(2)/2016(Ethics)/131118) and notified in the Gazette of India on October 08, 2016; the modification read as follows: "Use of generic names of drugs: Every physician should prescribe drugs with generic names legibly and preferably in capital letters and he/she shall ensure that there is a rational prescription and use of drugs." However, after the modification of Clause 1.5, the MCI circular No. MCI211(2 (Gen.)/2017-Ethics/104728 dated April 21, 2017 threatened doctors found suitable disciplinary action by the concerned state medical council or by the MCI.

Prescription written by the doctors has a significant impact on the usage of generic medicines, particularly in developing countries [18]. However, the safety and quality issues of generic products are of top concerns of general practitioners and health work professionals [19]. Doctor's viewpoint about generic medicines may pose a decisive hurdle to its large-scale usage, culminating in increased health-care expenses. Many healthcare providers may not have enough knowledge about generic medicines. For instance, healthcare providers may have concerns about safety and efficacy of generic medicines and sometimes this may be a major barrier to a wider use of these products. This attitude of healthcare providers is a significant challenge towards dealing with the rising healthcare cost [20]. Additionally pressures on physicians by the patients, commercial approach by the physicians while prescribing, money spinning persuasive activities by the pharmaceutical companies and lack of execution of stringent laws and regulations to curb such activities also play a very important role in preventing the use of generic medicines on a larger scale [21]. Internship is a phase of training wherein a graduate is expected to conduct actual practice of medical and health care as well as acquire skills under supervision so that he/she may become capable of functioning independently [22]. It is during this phase that attitudes of future physicians towards prescribing are developed. Therefore, understanding their perceptions about generic medicines may help in recognizing possible barriers to greater generic medicine usage. Studies elsewhere have indicated that it is often a challenge to change perception as well as the prescribing and dispensing behavior of healthcare providers about generics [23-25]. Medical educators have an important responsibility to teach the future doctors about the cost-effective use of medicines [26].

There is a great need in medical education to change attitudes especially for future health care providers as their current perception of generic medicine can impact their future prescribing and generic substitution pattern. Data regarding knowledge, attitude and practice of intern doctors for the use of generic medicines are lacking in our setup. Hence, the present study aimed to evaluate knowledge, attitude and practice (KAP) of intern doctors in a tertiary care teaching hospital regarding generic medicines.

\section{MATERIALS AND METHODS}

A questionnaire based cross sectional study was conducted in a tertiary care teaching hospital after prior approval of Institutional Ethics Committee. This study was conducted among intern doctors working in this hospital. The study duration was one month. Those intern doctors who were willing to respond to the study questionnaire were included in the study and those who were not willing or did not return the questionnaire were excluded. The questionnaire designed for this study comprised of 11 questions related to knowledge, attitude and practice of generic medicine and information regarding the demographic details of the participants. The questionnaire consisted of six questions pertaining to knowledge of generic medicine, three questions eliciting participants' attitude toward generic medicine and two questions related to practice of generic medicine. The questionnaire was pre-tested and validated by peer review and modifications suggested by them were incorporated.

The questionnaire prepared through google form was sent to intern doctors through email. The participants were asked to complete the questionnaire and submit it online. Those who failed to respond were reminded telephonically twice, firstly at the end of one week and secondly at the end of two weeks. Responses received till the end of fourth week were included in the analysis. Recorded information from the study participants was entered in Microsoft Excel Worksheet and data was analyzed in percentage and frequency. 


\section{RESULTS}

A total of 244 intern doctors were contacted and sent questionnaires out of which 163(66.80\%) agreed to participate and responded to the questionnaire in stipulated time. Among all of the respondents, 112 $(68.71 \%)$ were males and $51(31.28 \%)$ were females having a male: female ratio of 2.19: 1 . The participants were in the age range of 22-28years, with the majority being of 22 years $(50.4 \%)$ followed by 23 years $(37.2 \%)$ of age.

Responses of the questions evaluating the knowledge regarding the generic medicine is depicted in Table -1 . Out of six questions regarding knowledge of generic medicines majority of interns $(56.43 \%)$ were able to answer a total of either four or five questions appropriately while $1.22 \%$ intern doctors were not able to answer a single question appropriately. Knowledgerelated questions and their responses are summarized in Table-1.

A total of three questions showing attitude of interns towards generic medicines was asked to the participants. Majority of the interns (77.4\%) showed positive attitude towards prescribing generic drugs. Attitude-related questions and their responses are summarized in Table-2. A total of $83.4 \%$ intern doctors had prescribed generic medicines, $69.2 \%$ interns had prescribed branded medicines previously. Practice related questions and their responses are summarized in Table-3.

Table-1: Knowledge related questions

\begin{tabular}{|c|c|c|c|}
\hline Que & Question & \multicolumn{2}{|c|}{ Response $(n=163)$} \\
\hline \multirow[t]{4}{*}{1} & \multirow{4}{*}{$\begin{array}{l}\text { As per the Indian Medical Council Act (Professional conduct, Etiquette and } \\
\text { Ethics)Regulations- } 2002 \text { every physician should prescribe drugs by: } \\
\text { A. Brand name } \\
\text { B. Chemical name } \\
\text { C. Generic name } \\
\text { D. Branded generic name }\end{array}$} & A & $3(2 \%)$ \\
\hline & & $\mathrm{B}$ & $3(2 \%)$ \\
\hline & & $\mathrm{C}$ & $152(93 \%)$ \\
\hline & & $\mathrm{D}$ & $5(3 \%)$ \\
\hline \multirow[t]{3}{*}{2} & \multirow{3}{*}{$\begin{array}{l}\text { A generic medicine is made available once the product patent protection period } \\
\text { has been expired. Is this statement correct? }\end{array}$} & Yes & $99(60.9 \%)$ \\
\hline & & No & $31(19.1 \%)$ \\
\hline & & Can't say & $33(20 \%)$ \\
\hline \multirow[t]{5}{*}{3} & \multirow{5}{*}{$\begin{array}{l}\text { Which of the following statement(s) is true? (You may mark }[\sqrt{ }] \text { for more than } \\
\text { one correct response.) } \\
\text { A. Generic medicines are less efficacious compared to branded medicines. } \\
\text { B. Generic medicines can be used interchangeably with branded medicines in } \\
\text { most cases. } \\
\text { C. Generic medicines cause more adverse effects than branded medicines. }\end{array}$} & $\mathrm{A}$ & $18(11.04 \%)$ \\
\hline & & B & $119(73 \%)$ \\
\hline & & $\mathrm{C}$ & $4(2.45 \%)$ \\
\hline & & $\mathrm{A}$ and $\mathrm{B}$ & $17(10.43 \%)$ \\
\hline & & $\mathrm{A}$ and $\mathrm{C}$ & $5(3.06 \%)$ \\
\hline \multirow[t]{4}{*}{4} & \multirow{4}{*}{$\begin{array}{l}\text { From which of the following sources, Generic medicines can be purchased? } \\
\text { A. Government medical stores } \\
\text { B. Private medical stores } \\
\text { C. Online pharmacies } \\
\text { D. All of the above }\end{array}$} & $\mathrm{A}$ & $38(23.3 \%)$ \\
\hline & & B & $3(1.84)$ \\
\hline & & $\mathrm{C}$ & $1(0.7 \%)$ \\
\hline & & $\mathrm{D}$ & $121(74.2 \%)$ \\
\hline \multirow[t]{4}{*}{5} & \multirow{4}{*}{$\begin{array}{l}\text { Which one of the following scheme was initiated by government to promote } \\
\text { generic medicines in the market? } \\
\text { A. Man Aushadhi store } \\
\text { B. Jan Aushadhi store } \\
\text { C. Lok Aushadhi store } \\
\text { D. Jan seva store }\end{array}$} & A & $1(0.7 \%)$ \\
\hline & & $\mathrm{B}$ & $104(63.8 \%)$ \\
\hline & & $\mathrm{C}$ & $12(7.6 \%)$ \\
\hline & & $\mathrm{D}$ & $46(28.2 \%)$ \\
\hline \multirow[t]{3}{*}{6} & \multirow{3}{*}{$\begin{array}{l}\text { Which one of the following statement(s) is correct? } \\
\text { A. Use of generic medicine decreases overall healthcare expenditure. } \\
\text { B. Use of branded medicine decreases overall healthcare expenditure. } \\
\text { C. Use of either generic or branded medicine has same impact on overall } \\
\text { healthcare expenditure }\end{array}$} & $\mathrm{A}$ & $144(88.6 \%)$ \\
\hline & & $\mathrm{B}$ & $10(6.3 \%)$ \\
\hline & & $\mathrm{C}$ & $9(5.5 \%)$ \\
\hline
\end{tabular}


Alay K. Singhal et al; Saudi J Med Pharm Sci, Nov., 2019; 5(11): 972-978

Table-2: Attitude related questions

\begin{tabular}{|c|c|c|c|}
\hline $\begin{array}{l}\text { Que } \\
\text { No. }\end{array}$ & Question & \multicolumn{2}{|c|}{$\begin{array}{l}\text { Response } \\
(n=163)\end{array}$} \\
\hline \multirow[t]{4}{*}{1} & \multirow{4}{*}{$\begin{array}{l}\text { According to you, which of the following nomenclature is easier to memorize } \\
\text { medicines? } \\
\text { A. Brand name. } \\
\text { B. Generic name } \\
\text { C. Chemical name } \\
\text { D. Branded generic name }\end{array}$} & $\mathrm{A}$ & $24(14.7 \%)$ \\
\hline & & $\mathrm{B}$ & $127(78 \%)$ \\
\hline & & $\mathrm{C}$ & $6(3.68 \%)$ \\
\hline & & $\mathrm{D}$ & $6(3.68 \%)$ \\
\hline \multirow[t]{4}{*}{2} & \multirow{4}{*}{$\begin{array}{l}\text { You would prefer to prescribe medicine by: } \\
\text { A. Generic name } \\
\text { B. Brand name } \\
\text { C. Branded generic name } \\
\text { D. Chemical name }\end{array}$} & $\mathrm{A}$ & $126(77.4 \%)$ \\
\hline & & $\mathrm{B}$ & $17(10.4 \%)$ \\
\hline & & $\mathrm{C}$ & $17(10.4 \%)$ \\
\hline & & $\mathrm{D}$ & $3(1.8 \%)$ \\
\hline \multirow[t]{3}{*}{3} & \multirow{3}{*}{$\begin{array}{l}\text { According to you, which statement is true regarding availability of medicines? } \\
\text { A. Generic medicines are easily available. } \\
\text { B. Branded medicines are easily available. } \\
\text { C. Branded generic medicines are easily available. }\end{array}$} & $\mathrm{A}$ & $59(36.5 \%)$ \\
\hline & & $\mathrm{B}$ & $83(50.9 \%)$ \\
\hline & & $\mathrm{C}$ & $21(12.8 \%)$ \\
\hline
\end{tabular}

Table-3: Practice related questions

\begin{tabular}{|l|l|l|l|}
\hline $\begin{array}{l}\text { Que } \\
\text { No. }\end{array}$ & Question & \multicolumn{2}{l|}{ Response } \\
\hline 1 & Have you ever prescribed generic medicines? $(\mathrm{n}=163)$ & Yes & \multicolumn{1}{l|}{$\begin{array}{l}(36 \\
(83.4 \%)\end{array}$} \\
\cline { 3 - 4 } & & No & $27(16.6 \%)$ \\
\hline 2 & $\begin{array}{l}\text { If answer of Que-1 is yes, how often do you prescribe generic medicines? } \\
(\mathrm{n}=136)\end{array}$ & Always & $53(39.4 \%)$ \\
\cline { 3 - 4 } & & Sometimes & $70(51.4 \%)$ \\
\cline { 3 - 4 } & & Rarely & $13(9.5 \%)$ \\
\hline 3 & Have you ever prescribed branded medicines? $(\mathrm{n}=163)$ & Yes & $113(69.3 \%)$ \\
\cline { 3 - 4 } & & No & $50(30.7 \%)$ \\
\hline 4 & $\begin{array}{l}\text { If answer of Que-3 is yes, how often do you prescribe branded } \\
\text { medicines?(n=113) }\end{array}$ & Always & $9(7.9 \%)$ \\
\cline { 3 - 4 } & & Sometimes & $71(63 \%)$ \\
\cline { 3 - 4 } & & Rarely & $33(29.1 \%)$ \\
\hline
\end{tabular}

\section{DISCUSSION}

In present study an attempt was made to exclusively assess the knowledge and attitude of intern doctors regarding generic medicines and to what extent do they actually put into practice the use of generic medicines. Previously a study by Badwaik et al., in 2015 was conducted which included intern doctors along with other doctors in the hospital, however present study is different from it in the view that questionnaire was designed taking into consideration those aspects that were relevant exclusively to interns [22]. A total of $163(66.80 \%)$ interns responded to the questionnaire out of 244 interns contacted. This response rate is found similar to response rate of another study (73\%) done by Gupta SK et al., in 2015 [27].

Future prescribing patterns are greatly impacted by training received during undergraduate course and internship, so role of generic medicines in providing affordable health care should be taught during this period. According to the present analysis, good percentage of doctors had knowledge about generic medicines. Majority of the participants in our study had knowledge that generic medicines were intended to be interchangeable with branded medicines which was similar and showed an improvement of $10 \%$ to finding of other similar study by Gupta et al.in 2015, and $15 \%$ improvement to study by Badwaik et al. in 2015 [22, 27]. Moreover, various studies have reported that starting the therapy with generic medicines or switching to generic medicines is not related with poorer efficacy or safety [28, 29]. An assessment of data submitted to the USFDA, that compared clinical bioequivalence of orally administered generic medicines in single dose studies approved from 1996 to 2007, showed that there was no significant difference between generic and innovator products [30]. There is very little data available for Indian studies. In our study, most of the participating doctors were aware that generic medicines are only made available after the expiry date of the patent of the innovator. A high majority of intern doctors also had knowledge regarding the Indian Medical Council Act (Professional conduct, Etiquette and Ethics) Regulations, 2002, according to which every physician should prescribe drugs by generic name. This finding was similar to another study done by Bhattacharjee et al.in 2017 and showed improvement by $13 \%$ to finding of study done by, 
Gupta et al. in 2014 and an improvement of $25 \%$ to study by Badwaik et al.in 2015 [22, 27, 31].

The availability of good quality medicines at an affordable cost is a prime concern in a developing country like India. To address this concern, in November 2008 the Indian government initiated the Jan Aushadhi scheme with plan to expand it in all parts of India. Under this project the public-sector pharma companies supplied essential low-priced generic drugs to the Jan Aushadhi stores. This could be a model for the entire developing world if implemented successfully [32]. In our study most of the participants were aware of the Jan Aushadhi scheme initiated by the Indian government with a purpose to set up generic drug stores around the country which is contrary to the finding of Badwaik et al., [22]. Hence there is improvement regarding knowledge of Jan Aushadhi stores due to increased promotional activities by government and knowledge of generic medicines obtained during undergraduate course. Further awareness regarding Jan Aushadhi stores should be created in general public by means of running innovative awareness campaigns with help of media and other resources. Also majority of interns knew that generic medicines can be procured from multiple sources i.e. Government stores, private medical stores as well as online pharmacies. However in contrast to their knowledge regarding presence of multiple sources for procurement of generic medicines, more than half of the interns believed that branded medicines are more easily available as compared to generic medicines. According to another study by Badwaik et al., amidstall factors affecting prescription practices, lack of availability of generic medicines in pharmacy was the most important factor along with concern regarding efficacy and safety of generic medicines and lack of adequate information [22]. Addressing these issues can greatly enhance the use of generic medicines and should be emphasized. Hence ensuring sustained availability, having stringent laws for ensuring good quality products and growing overall awareness can increase confidence and use of generic medicines.

In developing countries, cost of therapy has a major role in deciding treatment and generic medicines help reduce the cost of treatment [33]. Majority of participants agree that use of generic medicines decreases overall healthcare expenditure. This finding was similar to findings of other studies done by Bhattacharjee et al.in2017, Gupta et al.in 2014 and Badwaik et al.in 2015 [22, 27, 31]. The cost of generic medicines has been found to be up to $91 \%$ less than that of the innovator medicine in India. This is due to the fact that generic medicines do not require to conduct the costly clinical trials like innovator drugs [18]. Most of the participants believe that generic medicines are as safe as branded drug which is similar to the finding of study done by Gupta SK et al., [27].
Majority of interns in present study said that they preferred to prescribe generic medicines. The major reasons behind their positive attitude were to provide affordable healthcare to patients and to provide more options to the patients in terms of choosing medicines. They also believed that it was easier to memorize medicines by generic names which was contradictory to another study by Bhatacharjee et al.in 2017 [31]. This contrasting view can be explained by the fact that the interns have very recently graduated from the medical school and their education laid emphasis on memorizing drugs by international nonproprietary names. In present study, we found that significantly more number of the interns prescribed generic medicines as compared to branded medicines. This can be explained by the fact that their prescriptions were not influenced by medical representatives and other financial incentives.

In present study, questionnaire was sent to respondent through email and submitted by them electronically. Hence, in person interview was not possible, that can be the major limiting factor. Furthermore, questionnaire did not include factors influencing prescribing of generic medicines in intern doctors.

\section{CONCLUSION}

The knowledge of intern doctor regarding definition, regulation and procurement of generic medicines was found to be adequate. They favour the use of generic medicines but believe that generic medicines are not as easily available as brand medicines and also prescribe generic medicines regularly. To conclude, large scale multicentric study with more detailed questionnaire required to validate the result of this study.

\section{Conflict of Interest: None}

\section{Source of Funding: Nil}

\section{REFERENCES}

1. Awaisu A., Kheir N., Ibrahim M. I. M., El-Hajj M., Hazi H., Khudair N., \& Barazi R. (2014). Knowledge, attitudes, and practices of community pharmacists on generic medicines in Qatar. International journal of clinical pharmacy, 36(2), 394-404.

2. Cumming J., Mays N., \& Daube J. (2010). How New Zealand has contained expenditure on drugs. Bmj, 340, c2441.

3. Tordoff J. M., Norris P. T., \& Reith D. M. (2008). "Price Management" and its impact on hospital pharmaceutical expenditure and the availability of medicines in New Zealand hospitals. Value in Health, 11(7), 1214-1226.

4. Chayna S. A study on the Knowledge, attitude and practice of generic medicines among the doctors in a tertiary care teaching hospital in north east India. 
J Pharmacovigil 2018, Volume 6. DOI: 10.4172/2329-6887-C1-033

5. Andrade C., \& Rao T. S. (2017). Prescription writing: Generic or brand?. Indian journal of psychiatry, 59(2), 133-137.

6. Lu Y., Hernandez P., Abegunde D., \& Edejer T. (2014). The World Medicines Situation 2011: Medicine Expenditures. Geneva: World Health Organization; 2011.

7. Hogerzeil H. V., \& Mirza Z. (2011). The World Medicines Situation 2011: Access to Essential Medicines as Part of the Right to Health; World Health Organization: Geneva, Switzerland, 680689.

8. Cameron A., Mantel-Teeuwisse A. K., Leufkens, H. G., \& Laing, R. O. (2012). Switching from originator brand medicines to generic equivalents in selected developing countries: how much could be saved?. Value in health, 15(5), 664-673.

9. What are generic drugs? (2019). [https://www.fda.gov/Drugs/ResourcesForYou/Co nsumers/Buying Using MedicineSafely/ GenericDrugs/ucm 167991.htm]. Last accessed on November 12, 2019.

10. McCormack J., \& Chmelicek J. T. (2014). Generic versus brand name: the other drug war. Canadian Family Physician, 60(10), 911.

11. World Health Organization. (2005). Multisource (Generic) Pharmaceutical Products: Guidelines on Registration Requirements to Establish Interchangeability. Working Document QAS/04.093/Rev. 4. Available from: http://www.who.int/medicines/ services/expert committees

/pharmprep/QAS04_093Rev4_final.pdf. [Last accessed on 2019 Oct 02].

12. Al-Gedadi N. A., Hassali M. A., \& Shafie A. A. (2008). A pilot survey on perceptions and knowledge of generic medicines among consumers in Penang, Malaysia. Pharmacy practice, 6(2), 93-97.

13. Chua G. N., Hassali M. A., Shafie A. A., \& Awaisu A. (2010). A survey exploring knowledge and perceptions of general practitioners towards the use of generic medicines in the northern state of Malaysia. Health policy, 95(2-3), 229-235.

14. Basak S. C., \& Sathyanarayana D. (2012). Exploring knowledge and perceptions of generic medicines among drug retailers and community pharmacists. Indian journal of pharmaceutical sciences, 74(6), 571-575.

15. Cameron A., Mantel-Teeuwisse A. K., Leufkens H. G., \& Laing R. O. (2012). Switching from originator brand medicines to generic equivalents in selected developing countries: how much could be saved?. Value in health, 15(5), 664-673.

16. Wong Z. Y., Hassali M. A., Alrasheedy A. A., Saleem F., Yahaya A. H., \& Aljadhey H. (2014).
Patients' beliefs about generic medicines in Malaysia. Pharmacy practice, 12(4).

17. Hassali M. A., Alrasheedy A. A., McLachlan A., Nguyen T. A., Al-Tamimi S. K., Ibrahim M. I. M., \& Aljadhey H. (2014). The experiences of implementing generic medicine policy in eight countries: a review and recommendations for a successful promotion of generic medicine use. Saudi pharmaceutical journal,22(6), 491503.

18. Hassali M. A., Shafie A. A., Jamshed S., Ibrahim M. I., \& Awaisu A. (2009). Consumers' views on generic medicines: a review of the literature. International Journal of Pharmacy Practice, 17(2), 79-88.

19. Colgan S., Faasse K., Martin L. R., Stephens M. H., Grey A., \& Petrie K. J. (2015). Perceptions of generic medication in the general population, doctors and pharmacists: a systematic review. BMJ open, 5(12), e008915.

20. Thompson C. A. (1996). Internet-based prescribing and dispensing trouble medical and pharmacy boards. American Journal Health Syst Pharm. 56:500-501.

21. Sukhlecha A. (2016). Medical internship: Is it a" one year paid leave" for postgraduate entrance examination preparation?. Medical Journal of Dr. DY Patil University, 9(6), 706.

22. Badwaik R. T., Chopade S. S., Mahajan H. M., \& Honrao R. (2015). Prescribers views on generic medicines: A study on knowledge, attitude and practice. J Cont Med A Dent, 3(2), 27-32.

23. Auta A., Bala E. T., \& Shalkur D. (2014). Generic medicine substitution: a cross-sectional survey of the perception of pharmacists in north-central, Nigeria. Medical Principles and Practice, 23(1), 53-58.

24. Hassali M. A., Shafie A. A., Awaisu A., Ibrahim M. I., Ping C. C., \& Jamshed S. (2010). Physicians' views on generic medicines: a narrative review. Journal of Generic Medicines, 7(1), 30-39.

25. Siam M. K. S., Khan A., \& Khan T. M. (2013). Medical and pharmacy students' knowledge and perceptions about generic medicines in B angladesh. Journal of Pharmaceutical Health Services Research, 4(1), 57-61.

26. Gafa M., Bilbija S., Martinova A., \& Bates I. (2002). Pharmacoeconomics: A view of EPSA member countries on issues related to awareness of the topic and the undergraduate curriculum. Pharmacy Education, 2(4), 171-175.

27. Gupta S. K., Nayak R. P., \& Vidyarthi S. K. (2015). A study on the knowledge, attitude, and practice of generic medicines among the doctors in a tertiary care teaching hospital in South India. National Journal of Physiology, Pharmacy and Pharmacology, 5(1), 39. 
28. Amit G., Rosen A., Wagshal A. B., Bonneh D. Y., Liss T., Grosbard A., . Efficacy of substituting innovator propafenone for its generic formulation in patients with atrial fibrillation. The American journal of cardiology, 93(12), 1558-1560.

29. Araszkiewicz A. A., Szabert K., Godman B., Wladysiuk M., Barbui C., \& Haycox A. (2008). Generic olanzapine: health authority opportunity or nightmare? Expert review of pharmacoeconomics \& outcomes research, 8(6), 549-555.

30. Davit B. M., Nwakama P. E., Buehler G. J., Conner D. P., Haidar S. H., Patel D. T., . \& Woodcock J. (2009). Comparing generic and innovator drugs: a review of 12 years of bioequivalence data from the United States Food and Drug Administration. Annals of Pharmacotherapy, 43(10), 1583-1597.

31. Bhattacharjee P., Das L., Ghosh R., Das U. K., Chakraborty M., \& Bhattacharjee P. (2017). Knowledge, attitude and practice of generic medicines among doctors in a tertiary care teaching hospital of Tripura, India. Int J Basic Clin Pharmacol, 6, 1287-92.

32. Jayaraman K. (2010). Troubles beset'Jan Aushadhi'plan to broaden access to generics. Nat Med. 16:350.

33. Zaverbhai K. D., Dilipkumar K. J., Kalpan D. C., \& Kiran D. M. (2017). Knowledge, Attitude and Practice of Resident Doctors for use of Generic Medicines at a Tertiary care Hospital. Journal of Young Pharmacists, 9(2),263-266. 